\title{
Process intensification through microbial strain evolution: mixed glucose-xylose fermentation in wheat straw hydrolyzates by three generations of recombinant Saccharomyces cerevisiae
}

Vera Novy, Stefan Krahulec, Manfred Wegleiter, Gerdt Müller, Karin Longus, Mario Klimacek and Bernd Nidetzky

\begin{abstract}
Background: Lignocellulose hydrolyzates present difficult substrates for ethanol production by the most commonly applied microorganism in the fermentation industries, Saccharomyces cerevisiae. High resistance towards inhibitors released during pretreatment and hydrolysis of the feedstock as well as efficient utilization of hexose and pentose sugars constitute major challenges in the development of $S$. cerevisiae strains for biomass-to-ethanol processes. Metabolic engineering and laboratory evolution are applied, alone and in combination, to adduce desired strain properties. However, physiological requirements for robust performance of S. cerevisiae in the conversion of lignocellulose hydrolyzates are not well understood. The herein presented S. cerevisiae strains IBB10A02 and IBB10B05 are descendants of strain BP10001, which was previously derived from the widely used strain CEN.PK 113-5D through introduction of a largely redox-neutral oxidoreductive xylose assimilation pathway. The IBB strains were obtained by a two-step laboratory evolution that selected for fast xylose fermentation in combination with anaerobic growth before (IBB10A02) and after adaption in repeated xylose fermentations (IBB10B05). Enzymatic hydrolyzates were prepared from up to 15\% dry mass pretreated (steam explosion) wheat straw and contained glucose and xylose in a mass ratio of approximately 2.

Results: With all strains, yield coefficients based on total sugar consumed were high for ethanol ( 0.39 to $0.40 \mathrm{~g} / \mathrm{g}$ ) and notably low for fermentation by-products (glycerol: $\leq 0.10 \mathrm{~g} / \mathrm{g}$; xylitol: $\leq 0.08 \mathrm{~g} / \mathrm{g}$; acetate: $0.04 \mathrm{~g} / \mathrm{g}$ ). In contrast to the specific glucose utilization rate that was similar for all strains $\left(q_{\text {Glucose }} \approx 2.9 \mathrm{~g} / \mathrm{g}_{\text {cell }}\right.$ dry weight $(\mathrm{CDW} / \mathrm{h})$, the xylose consumption rate was enhanced by a factor of 11.5 (IBB10A02; 9 xylose $\left.=0.23 \mathrm{~g} / \mathrm{g}_{\mathrm{cDw}} / \mathrm{h}\right)$ and 17.5 (IBB10B05; $9_{\text {xylose }}=0.35 \mathrm{~g} / \mathrm{g}_{\mathrm{CDW}} / \mathrm{h}$ ) as compared to the $9_{\text {xylose }}$ of the non-evolved strain BP10001. In xylose-supplemented $(50 \mathrm{~g} / \mathrm{L})$ hydrolyzates prepared from 5\% dry mass, strain IBB10B05 displayed a 9xylose of $0.71 \mathrm{~g} / \mathrm{g}_{\mathrm{cDW}} / \mathrm{h}$ and depleted xylose in 2 days with an ethanol yield of $0.30 \mathrm{~g} / \mathrm{g}$. Under the conditions used, IBB10B05 was also capable of slow anaerobic growth.
\end{abstract}

Conclusions: Laboratory evolution of strain BP10001 resulted in effectively enhanced 9 xylose at almost complete retention of the fermentation capabilities previously acquired by metabolic engineering. Strain IBB10B05 is a sturdy candidate for intensification of lignocellulose-to-bioethanol processes.

\footnotetext{
* Correspondence: bernd.nidetzky@tugraz.at

Institute of Biotechnology and Biochemical Engineering, Graz University of Technology, Petersgasse 12/l, 8010 Graz, Austria
} 


\section{Background}

Second-generation biofuel production aims at biotechnological conversion of lignocellulosic biomass into liquid fuels, typically ethanol. Processes currently advancing to commercial scale production are facing two problems in particular. Firstly, for an efficient release of fermentable sugars from the insoluble feedstock, a technically complex and energy-intensive series of upstream processing steps are required [1-3]. Hence, mechanical and thermochemical pretreatment methods, alone or in combination, are applied to degrade and remove the lignin and to enhance the accessibility of the structural carbohydrates hemicellulose and cellulose for the subsequent enzymatic hydrolysis. During this pretreatment, however, secondary decomposition processes lead to formation of by-products, for example furans, phenolic compounds and organic acids, and many of those are inhibitory or even toxic to microorganisms applied to sugar fermentation [1-3]. It is widely accepted therefore that lignocellulose hydrolyzates constitute exceptionally difficult substrates for biotechnological conversions $[1,2,4,5]$. Since intermediate purification of the hydrolyzate is usually not a viable process option, a key requirement for efficient second-generation bioethanol production is a microbial strain that combines useful fermentation capabilities with high robustness to the overall conditions of the hydrolyzate $[1,2,4,5]$. Saccharomyces cerevisiae is a sturdy ethanol producer with long-standing history in the fermentation industries. Among the different candidate microorganisms considered, therefore, S. cerevisiae stands out as a highly promising choice for industrial scale applications [6].

Even though the composition of fermentable sugars in lignocellulose hydrolyzates varies strongly depending on the feedstock and the upstream processing technology applied, it is typical for most substrates to contain a significant amount of xylose next to the main glucose [1]. A major limitation of S. cerevisiae for lignocellulosic bioethanol development is the organism's natural inability to utilize xylose. Metabolic engineering has therefore been key in the development of xylose-fermenting strains of S. cerevisiae [2,5-8]. The applied strategies can be classified broadly according to whether xylose assimilation, which occurs through net isomerization of xylose into xylulose, was achieved via two-step oxidoreductive or direct isomerase-catalyzed transformation, as shown in Figure 1 [9-13]. Recombinant strains derived from either strategy displayed the expected broadening of substrate scope towards xylose. However, their specific xylose uptake rates and ethanol formation rates were still very low in comparison to the corresponding specific rates on glucose [5-7]. Moreover, xylose fermentation capabilities were usually severely deteriorated upon switching from synthetic substrate conditions to the harsher

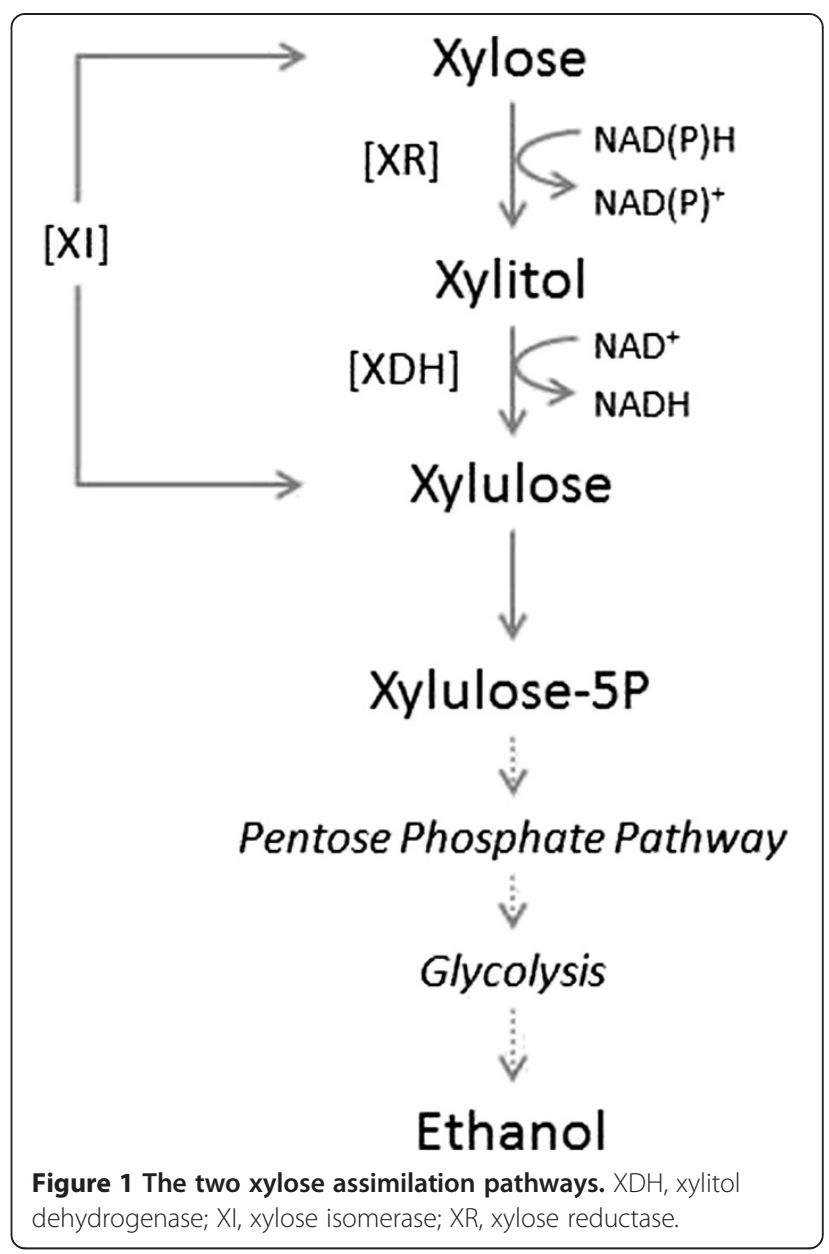

conditions of a lignocellulosic hydrolyzate $[2,6,8,14]$. A particular downside of strains harboring the oxidoreductive pathway is that a substantial amount of xylose is converted to xylitol and thus lost for ethanol production. Xylitol by-product formation is widely believed to have its origin in a mismatched coenzyme usage, NADP or NAD, during xylose reduction and xylitol oxidation (Figure 1) [11,15-19]. Coenzyme specificity engineering in xylose reductase $(\mathrm{XR}$; NADPH $\rightarrow \mathrm{NADH})$ and xylitol dehydrogenase $\left(\mathrm{XDH} ; \mathrm{NAD}^{+} \rightarrow \mathrm{NADP}^{+}\right)$was useful to render the two-step isomerization of xylose a more nearly redoxneutral process (Figure 1) [15-17,20]. However, aside from the intended change in coenzyme specificity, engineered enzymes must also fulfill the requirement of good activity under physiological boundary conditions in vivo. Due to their favorable kinetic properties that include high turnover number and apparent substrate and coenzyme affinities well aligned to intracellular metabolite concentrations in xylose-fermenting S. cerevisiae, some of the reported XR variants are especially promising for strain development. This is exemplified clearly by strain BP10001 from this laboratory that harbors an optimized NADH-preferring mutant of Candida tenuis XR. BP10001 shows a xylitol yield 
$\left(Y_{\text {Xylitol }}\right)$ more than halved by comparison to $Y_{\text {Xylitol }}$ in the reference strain BP000 that expresses the NADPHpreferring wild-type XR [16,18-22]. Importantly, the lowering of $Y_{\text {Xylitol }}$ in BP10001 was not achieved in a trade-off against a decrease in xylose uptake rate $\left(q_{\text {Xylose }}\right)[20,22]$. However, $q_{\text {xylose }}$ of strain BP10001 was still almost two magnitude orders lower than the corresponding $q_{\text {Glucose }}$ and it was certainly insufficient for viable co-fermentation of glucose and xylose [20,22]. It must be emphasized that low $q_{\text {xylose }}$ is a common problem of xylose-fermenting strains of $S$. cerevisiae, regardless of the metabolic engineering strategy applied in their construction $[6,7,13]$.

The specific substrate consumption rate is a kinetically complex rate parameter, which often eludes clear-cut dissection into one or more rate-determining transport or reaction steps, these in turn presenting distinct targets for further metabolic engineering. Laboratory evolution presents a long-known method for physiology optimization in microorganisms, and it has recently been adapted as a powerful complement of metabolic engineering to the development of high $q_{\text {xylose }}$ strains of $S$. cerevisiae [23-26]. Improvements in $q_{\text {xylose of up to }}$ one magnitude order were achieved using evolutionary engineering, and strains capable of co-utilization of glucose and xylose, and of cellobiose and xylose were obtained [25-28]. Interestingly, some strains also acquired the ability of slow anaerobic growth as a result of the evolution, presumably as a consequence of the enhanced ATP production rate at elevated $q_{\text {xylose }}[25,26]$. Moreover, resistance to the overall environment of lignocellulose hydrolyzates or certain compounds present in it (for example furfural, acetic acid) could also be improved substantially by evolutionary engineering [23,29].

We have therefore applied laboratory evolution to strain BP10001 and used specific anaerobic growth rate ( $\left.\mu_{\text {Xylose }}\right)$ in combination with high $q_{\text {Xylose }}$ to select strain IBB10A02 from several anaerobically growing yeast strains thus obtained. Further strain adaption through multiple rounds of batch xylose fermentations resulted in the identification of strain IBB10B05. The two evolved strains plus their parent strain BP10001 were compared in mixed glucose-xylose fermentation of undiluted and non-detoxified wheat straw hydrolyzate, which represents a notably challenging substrate. In Europe, wheat straw is considered to have the highest potential as biomass source for bioethanol production due to its abundance and low cost [30]. Even though wheat straw hydrolyzates have already been utilized as substrate for bioethanol production in the past, efficient xylose conversion often had complex process requirements, for example simultaneous saccharification and fermentation (SSF) [31,32] or fed-batch processing [33]. Therefore, further improvement in xylose conversion rates and higher ethanol yields at lower by-product formation must still be rendered possible [4-6,29,34]. To ensure optimal conditions for xylose fermentation and to keep technical requirements to a minimum level the process was run as separate hydrolysis and co-fermentation (SHCF) with the fermentation accomplished in simple batch cultures $[33,34]$. Results presented in this paper delineate marked gain in xylose fermentation efficiency and overall substrate tolerance due to evolutionary engineering, and strain IBB10B05 was identified as a promising candidate for direct glucose-xylose fermentation in unprocessed wheat straw hydrolyzate.

\section{Results and discussion}

\section{Composition of the feedstock, and preparation of the} sugar substrate for fermentation

Steam explosion has been described as an efficient and cost-effective method for the pretreatment of wheat straw [3,31-36]. Auxiliary chemical treatment is often applied to reinforce effectiveness of the steam explosion. We have applied here simple pretreatment based on steam explosion only. Table 1 shows the results of compositional analysis of the wheat straw after pretreatment. Dry matter content was about $20 \%$, the water-insoluble portion thereof being roughly 68\%. Pretreated feedstock composition was in agreement with literature data on wheat straw samples from different origin, but processed similarly $[32,34,35]$.

Mixed sugar substrates for yeast fermentation were prepared by enzymatic saccharification of the pretreated wheat straw at a dry matter loading of $5 \%$ or $15 \%$ (by weight). Both fermentations were accomplished at the same boundary conditions, for example $\mathrm{pH}$, temperature, agitation and starting $\mathrm{OD}_{600}$. However, medium supplementation and sugar composition (glucose and xylose ratio) varied between the two hydrolyzates. We noticed that regardless of substrate and enzyme loadings applied to the saccharification, the resulting hydrolyzates always contained double the amount of glucose compared to xylose. Thus, 5\% hydrolyzates contained glucose and xylose in concentrations of approximately $14 \mathrm{~g} / \mathrm{L}$ and $7 \mathrm{~g} / \mathrm{L}$,

\begin{tabular}{|c|c|}
\hline Component in dry matter & Percentage (\%) \\
\hline \multicolumn{2}{|l|}{ Carbohydrates } \\
\hline Glucose & 47.8 \\
\hline Xylose & 21.3 \\
\hline Others & 2.8 \\
\hline \multicolumn{2}{|l|}{ Non-carbohydrates } \\
\hline Acid-soluble lignin & 3.8 \\
\hline Acid-insoluble lignin & 18.0 \\
\hline Ashes & 1.5 \\
\hline
\end{tabular}


respectively. To investigate xylose fermentation at elevated xylose/glucose (Xyl/Glc) ratio, like done in various studies from this and other groups in the past $[32,34,35]$, we supplemented the $5 \%$ hydrolyzate to a final xylose concentration of approximately $50 \mathrm{~g} / \mathrm{L}$, resulting in a Xyl/Glc ratio of approximately 4. Mineral media, containing salts, vitamins and trace elements, was added to $5 \%$ hydrolyzates to ensure optimal fermentation conditions and maximal viability of the yeast $[24,32,35]$. However, in any larger scale process media additives such as salts or vitamins are economically and procedurally not feasible $[2,14,37]$. To address this problem, further fermentation studies were conducted under most simplified process and substrate conditions in the highly concentrated, non-detoxified $15 \%$ hydrolyzate with yeast extract as sole media supplement. As described previously, yeast extract serves as an excellent complex media additive for the fermentation of wheat straw hydrolyzates with high dry matter loadings [38]. Economically advantageous solutions, such as corn steep liquor or urea, in contrast, were described to be insufficient for wheat straw to bioethanol processes [38]. In this study, yeast extract served as a model for complex media supplementation, replacing the expensive mineral medium. However, addition of cheaper nutrient and nitrogen sources, for example grass juice, are future targets for process optimization.

Utilization of high substrate loadings is beneficial for lignocellulosic bioethanol production since the increase in sugar content (here: approximately $40 \mathrm{~g} / \mathrm{L}$ and $20 \mathrm{~g} / \mathrm{L}$ glucose and xylose, respectively in the $15 \%$ hydrolyzate) results in higher ethanol titers, which is important for facilitation of downstream processing. Throughout the manuscript, the sugar substrates used are identified as $15 \%$ hydrolyzate and $5 \%$ hydrolyzate ${ }_{X}$, where subscript ' $\mathrm{x}$ ' indicates externally added xylose.

\section{Effect of S. cerevisiae strain evolution on xylose fermentation in basal medium}

Strains IBB10A02 and IBB10B05 were obtained by laboratory evolution as described under Methods. The two strains were compared to their progenitor strain BP10001 by evaluating xylose $(58 \mathrm{~g} / \mathrm{L})$ utilization in anaerobic shaken flask cultures. Time courses of fermentation product formation and biomass growth during xylose conversion were recorded for each strain, and the results are shown in Additional file 1. Compared to BP10001, the evolved strains displayed enhanced xylose fermentation capabilities in several respects. First of all, xylose consumption was markedly accelerated due to the combined effects of a distinct ( $\geq 2.5$-fold) increase in $q_{\text {xylose }}$ and the establishment of anaerobic growth caused by the laboratory evolution (Table 2). $q$ xylose values of about $1.0 \mathrm{~g} / \mathrm{g}_{\mathrm{CDW}} / \mathrm{h}$ are among the highest reported for xylose-fermenting strains of S. cerevisiae [9,11,22,23,26,39].
Table 2 Comparison of $\mu_{\max }$ and $\boldsymbol{q}_{\text {xylose }}$ of strains BP10001, IBB10A02 and IBB10B05 obtained from xylose fermentation in YX medium

\begin{tabular}{llll}
\hline Parameter & BP10001 & IBB10A02 & IBB10B05 \\
\hline$q_{\text {xylose }}\left(\mathrm{g} / \mathrm{g}_{\mathrm{CDW}} / \mathrm{h}\right)$ & $0.37 \pm 0.05$ & $0.98 \pm 0.08$ & $1.04 \pm 0.06$ \\
$\mu_{\max }\left(\mathrm{h}^{-1}\right)$ & n.d. & $0.017 \pm 0.001$ & $0.021 \pm 0.001$ \\
\hline
\end{tabular}

Data was obtained from two independent fermentations. n.d., not detectable.

Strain IBB10B05 grew faster and to a higher biomass concentration than strain IBB10A02 (Table 2, Additional file 1). In both strains, however, the specific growth rate on xylose ( $\left.\mu_{\text {Xylose }}\right)$ decreased strongly as xylose conversion progressed. Growth ceased completely at extended fermentation time $(\geq 120 \mathrm{~h})$, even though more than half of the initial xylose was still present and utilization of the sugar substrate continued further on. Considering that $q_{\text {xylose }}$ also decreased appreciably over the fermentation time course, shutdown of growth may reflect a drop of $q_{\text {xylose }}$ (and the ATP production rate associated with it) below a critical value. Additionally to its effects on key rate parameters of the fermentation (Table 2), we further analyzed the effect of laboratory evolution on the product distribution pattern of external metabolites produced from xylose. Data are summarized in Additional file 2. For all three yeast strains, the ethanol yield coefficient $\left(Y_{\text {Ethanol/Xylose }}\right)$ was approximately $0.31 \mathrm{~g} / \mathrm{g}$. Yield coefficients for glycerol $\left(Y_{\text {Glycerol } / \text { Xylose }}\right)$ were also similar for strains BP10001, IBB10A02 and IBB10B05 at approximately $0.04 \mathrm{~g} / \mathrm{g}$. Observed xylitol yields ( $Y_{\text {Xylitol } /}$ Xylose) were comparable for strain BP10001 and IBB10A02 $(0.15 \mathrm{~g} / \mathrm{g})$ and increased 1.3-fold in fermentation utilizing strain IBB10B05 $(0.19 \mathrm{~g} / \mathrm{g})$. The yield coefficients for strain BP10001 agree well with previously published results [22], indicating that the switch from mineral to yeast extract medium had no influence on product formation. Accordingly, mixed glucose-xylose conversion in spent sulfite liquor utilizing IBB10B05 was not affected by replacing mineral media with yeast extract [40]. Results of fermentation of xylose as the sole sugar substrate (Additional files 1 and 2, Table 2) strongly supported application of the two evolved yeast strains for mixed glucose-xylose conversion in wheat straw hydrolyzates. Conditions in the lignocellulose hydrolyzate are however noteworthy different from those of a pure glucose-xylose substrate (see, for example Palmqvist and Hahn-Hägerdal [4], Hahn-Hägerdal et al. [6], Casey et al. [41]), and the switch from defined to technological sugar substrates has proven to be difficult in the past $[2,4,6]$.

\section{Mixed glucose-xylose fermentation in xylose enriched $5 \%$ hydrolyzate : laboratory evolution results in markedly accelerated xylose utilization}

A detailed time-course analysis for glucose-xylose fermentation in $5 \%$ hydrolyzate $_{\mathrm{X}}$ was performed, comparing the 
two evolved S. cerevisiae strains to the BP10001 reference. Results are summarized in Figure 2. All strains utilized glucose much faster than xylose. For clarity reasons, therefore, the respective 'glucose phase' was singled out and is shown in a separate graph (Additional file 3) depicting only the first phase (approximately $8 \mathrm{~h}$ ) of the fermentation course. Determination of a specific glucose utilization rate $\left(q_{\text {Glucose }}\right)$ for each strain was hampered due to rapid substrate depletion. However, time resolution of the shown data (Additional file 3) was sufficient to clarify that the three yeast strains consumed glucose at a comparable rate. Ethanol production $\left(Y_{\text {Ethanol }}=\right.$ approximately $\left.0.40 \mathrm{~g} / \mathrm{g}\right)$ and glycerol formation $\left(Y_{\text {Glycerol }}=\right.$ approximately $\left.0.06 \mathrm{~g} / \mathrm{g}\right)$ in the glucose phase were also similar for the different strains (Additional file 3$)$. The specific growth rate $\left(\mu_{\text {Glucose }}\right)$ for strain IBB10B05 approached a value expected for uninhibited $S$. cerevisiae growth during glucose fermentation, while in strains IBB10A02 and BP10001, the $\mu_{\text {Glucose }}$ values were notably decreased (Table 3 ). This provided the first evidence that strain IBB10B05 had gained superior resistivity to the conditions of the wheat straw hydrolyzate. Overall, IBB10B05 grew to a biomass concentration of approximately $2.6 \mathrm{~g} / \mathrm{L}$, which is significantly higher than reported for other yeast strains under comparable substrate conditions [34].

Evaluation of the second phase of the fermentation time courses, where xylose was utilized (Figure 2), revealed significant differences between the two evolved strains and their progenitor strain. The corresponding rate parameters and yield coefficients are summarized in Table 3. $q_{\text {xylose }}$ of IBB10A02 was enhanced 3.5-fold as compared to BP10001. IBB10B05 even surpassed IBB10A02 in terms of $q$ xylose. The switch from pure xylose substrate to $5 \%$ hydrolyzate ${ }_{X}$ caused a 2.5 -fold decrease in $q_{\text {xylose }}$ for BP10001. In contrast, the evolved strains, particularly IBB10B05, showed a much less pronounced drop in $q_{\text {xylose }}($ Table 3$)$. It is noteworthy that both evolved strains consumed nearly all of the offered $50 \mathrm{~g} / \mathrm{L}$ xylose within approximately 2 days. BP10001 by contrast showed much smaller xylose utilization $(\leq 10 \mathrm{~g} / \mathrm{L})$ in the same time frame (Figure 2$)$. Yield coefficients were similar for each strain, as shown in Table 3 where yield coefficients were calculated on the basis of total sugar, glucose and xylose consumed. Considering bias in the calculated yield coefficients due to unequal xylose utilization by BP10001 as compared to the evolved strains, we compiled a second set of yield coefficients (Additional file 4), which were determined from the xylose phase only, starting when the glucose was depleted fully. $Y_{\text {Ethanol } / \text { Xylose }}$ was about $0.31 \pm 0.01 \mathrm{~g} / \mathrm{g}$ in all strains and xylitol was the main by-product with $Y_{\text {Xylitol/ }}$ Xylose in the range 0.18 to $0.23 \mathrm{~g} / \mathrm{g}$. Even though loss of xylose into xylitol formation was substantial with all three strains examined and therefore presents a clear target for strain optimization in the future, it is nevertheless worth noting that $Y_{\text {Xylitol/Xylose }}$ was not affected by change in substrate from pure xylose to $5 \%$ hydrolyzate $_{\mathrm{X}}$. It was previously shown that enhanced burden on
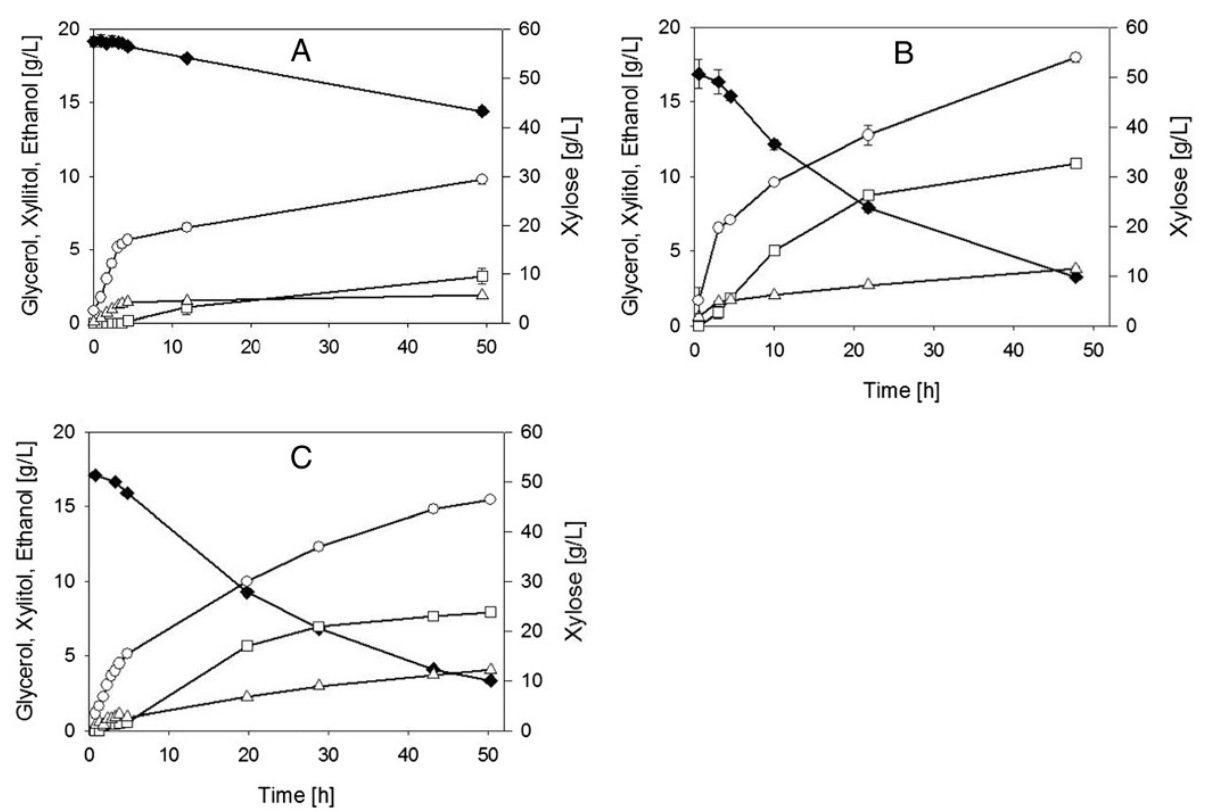

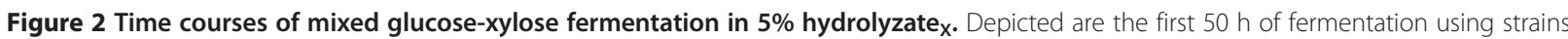
(A) BP10001, (B) IBB10A02 and (C) IBB10B05. Glucose (approximately $14 \mathrm{~g} / \mathrm{L}$ ) was depleted within the first $5 \mathrm{~h}$ and the 'glucose phase' is shown in Additional file 3. Data points are mean values of two independent fermentation experiments. Full diamonds, xylose; empty triangles, glycerol; empty squares, xylitol; empty circles, ethanol. 
Table 3 Physiological parameters of strains BP10001, IBB10A02 and IBB10B05 obtained from mixed glucose-xylose fermentation in $\mathbf{5 \%}$ hydrolyzate $x$

\begin{tabular}{lccc}
\hline Parameter & BP10001 & IBB10A02 & IBB10B05 \\
\hline$q_{\text {Glucose }}\left(\mathrm{g} / \mathrm{g}_{\mathrm{CDW}} / \mathrm{h}\right)$ & $\mathrm{n} . \mathrm{d}$. & $\mathrm{n} . \mathrm{d}$. & $\mathrm{n} . \mathrm{d}$. \\
$q_{\text {Xylose }}\left(\mathrm{g} / \mathrm{g}_{\mathrm{CDW}} / \mathrm{h}\right)$ & $0.15 \pm 0.01$ & $0.53 \pm 0.05$ & $0.71 \pm 0.01$ \\
$\mu_{\max }^{\mathrm{a}}$ & $0.09 \pm 0.01$ & $0.13 \pm 0.02$ & $0.43 \pm 0.03$ \\
$Y_{\text {Ethanol }}(\mathrm{g} / \mathrm{g})$ & 0.35 & 0.31 & 0.30 \\
$\left(Y_{\text {Ethanol/available sugars }}(\mathrm{g} / \mathrm{g})\right)^{\mathrm{b}}$ & $(0.18)$ & $(0.25)$ & $0.29)$ \\
$Y_{\text {Glycerol }}(\mathrm{g} / \mathrm{g})$ & 0.06 & 0.06 & 0.09 \\
$Y_{\text {Xylitol }}(\mathrm{g} / \mathrm{g})$ & 0.15 & 0.22 & 0.17 \\
$Y_{\text {Acetate }}(\mathrm{g} / \mathrm{g})$ & 0.04 & 0.06 & 0.05 \\
$Y_{\text {BM }}(\mathrm{g} / \mathrm{g})$ & 0.02 & 0.03 & 0.04 \\
C-recovery $(\%)$ & $98 \pm 1$ & $102 \pm 1$ & $96 \pm 1$ \\
\hline
\end{tabular}

Data was obtained from two independent fermentations, mean errors of product coefficients were always below $11 \%$. Fermentation time courses are shown in Figure 2 . Fermentation in $5 \%$ hydrolyzate ${ }_{x}$ : glucose to xylose ratio of approximately $0.2{ }^{\text {a }}$ Determined in the first 4.5 hours of fermentation; ${ }^{b}$ $Y_{\text {Ethanol/available sugars }}=\mathrm{c}($ Ethanol produced in $100 \mathrm{~h}$ of fermentation $) / \mathrm{c}$ (Available glucose and xylose). Note that utilization of xylose was much lower in strain BP10001 than it was in the evolved strains. This affects the calculated ethanol yield coefficient based on total sugar (glucose and xylose) consumed. The ethanol yield coefficient was therefore also expressed based on total sugars available in the reaction, as shown in parenthesis. n.d., not detectable.

yeast physiology under conditions of a technological substrate could not only affect $q_{\text {xylose }}$, but also result in increased xylitol yields at the expense of ethanol production [40]. In fact, this effect was also observed when substrate was altered from $5 \%$ hydrolyzate $\mathrm{x}$ to $15 \%$ hydrolyzate, as we will show hereinafter. Ethanol formation was almost doubled in the evolved strains compared to BP10001, whereby strain IBB10A02 accumulated up to $18 \mathrm{~g} / \mathrm{L}$ ethanol within 2 days (Figure 2). The slightly smaller volumetric ethanol production by strain IBB10B05 compared to strain IBB10A02 is ascribed to experimental differences in the biomass concentration at the time of inoculation. Based on total sugar consumed, the obtained ethanol yield was about $70 \%$ of the theoretical value. Contrary to fermentations carried out with pure sugar substrate (Table 2), none of the three strains showed anaerobic growth on xylose in the $5 \%$ hydrolyzate . Although cell growth is an important feature of $S$. cerevisiae strains applied to lignocellulose-to-bioethanol processes $[6,7,26]$, growth rates ( $\mu_{\text {Glucose }}$ and $\left.\mu_{\text {Xylose }}\right)$ are often excluded in literature [31-33,35], leading to the assumption that those yeast strains might have been growth impaired [34].

\section{Mixed glucose-xylose fermentation in undiluted and non-detoxified $15 \%$ hydrolyzate: laboratory evolution confers a high degree of strain robustness}

Results showing that laboratory evolution had caused enhancement of $q_{\text {Xylose }}$ and consolidated anaerobic growth (on glucose) without compromising ethanol yield during mixed glucose-xylose fermentation of the $5 \%$ hydrolyzate prompted us to take conversion experiments to another level of substrate complexity. Impairment of xylose fermentation in recombinant $S$. cerevisiae was previously described, when applying undiluted substrate at similar concentration as presented in this study [24,34,35], and this will also be confirmed for strain BP10001 hereinafter. Fermentation time courses recorded with the two evolved strains and strain BP10001 are shown in Figure 3. Specific rate and yield parameters calculated from the data are summarized in Table 4.

A recurring pattern in the fermentation time courses in Figure 3 was their division into two phases according to sugar substrate utilization. Glucose was consumed much faster than xylose. At the resolution of the experimental data with respect to time and concentration, sugar consumption appeared to have been largely sequential, glucose prior to xylose. It was shown in prior studies of BP10001 and also other xylose-fermenting strains of S. cerevisiae that low concentrations of glucose stimulate the uptake of xylose and only under these conditions a significant amount of true co-utilization of glucose and xylose becomes eventually possible [22,42]. However, at glucose concentrations at or higher than $5 \mathrm{~g} / \mathrm{L}$, xylose consumption is inhibited [22,42]. The evolved strains IBB10A02 and IBB10B05 do in fact show a small amount of glucose-xylose co-utilization at the end of their respective glucose phase (Figure 3). Strain BP10001 utilizes xylose at a much slower rate by comparison, thus resulting in a completely sequential fermentation pattern.

Recently S. cerevisiae harboring xylose isomerase (Figure 1) was evolved to a $q_{\text {xylose }}$ exceeding that of IBB10B05 in pure xylose substrate by still a factor of about 2 [39]. Glucose-xylose fermentation by the resulting yeast strain occurred at the transition between sequential and simultaneous utilization of hexose and pentose substrates, indicating that true co-fermentation may become possible at sufficiently high $q_{\text {Xylose }}$. However, fermentation of lignocellulose hydrolyzates was not examined, and evidence from this study suggests that $q_{\text {xylose }}$ is more strongly affected by substrate conditions than $q_{\text {Glucose }}$. Moreover, a number of publications on mixed glucose-xylose fermentation in lignocellulose hydrolyzates by recombinant $S$. cerevisiae, typically strains constructed using the XR/XDH pathway, agree with our findings of predominantly sequential sugar substrate utilization [33-35].

Even though fermentation of glucose was fast in each case (Figure 3), the three yeast strains differed in respect to $q_{\text {Glucose }}$ and $\mu_{\text {Glucose }}$, thus resulting in distinctly different efficiencies of glucose conversion. Strain IBB10B05 showed the highest $\mu_{\text {Glucose }}$ and the fastest glucose utilization (Figure 3, Table 4). $q_{\text {Glucose }}$ of strain IBB10A02 was surprisingly low. Analysis of the xylose phase from 

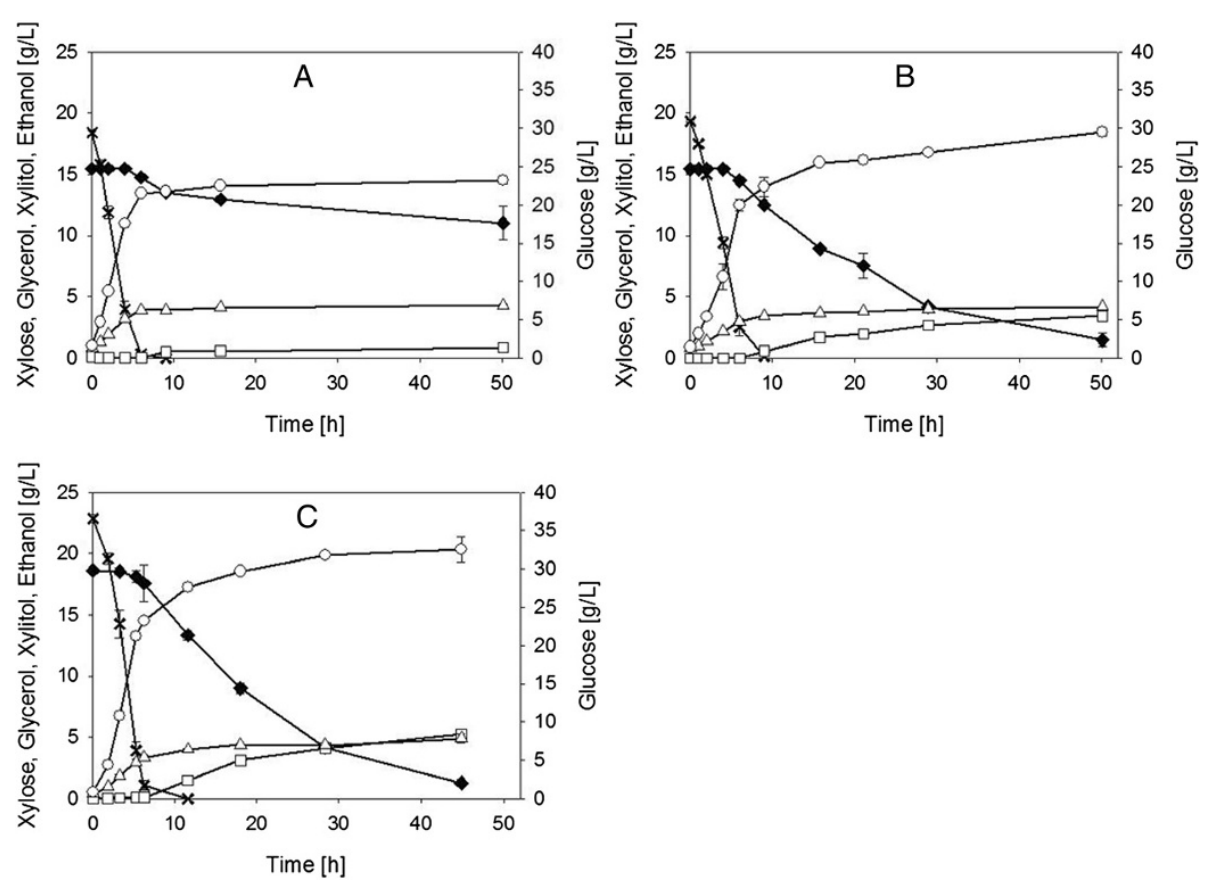

Figure 3 Time courses of mixed glucose-xylose fermentation in $\mathbf{1 5 \%}$ hydrolyzate. Depicted are the first $50 \mathrm{~h}$ of fermentation utilizing strains (A) BP10001, (B) IBB10A02 and (C) IBB10B05. Data points are mean values of two independent fermentation experiments. Crosses, glucose; full diamonds, xylose; empty triangles, glycerol; empty squares, xylitol; empty circles, ethanol.

the $15 \%$ hydrolyzate conversion time course revealed dramatic effects of laboratory evolution on the yeast strains' xylose fermentation capabilities. While the progenitor strain BP10001 was utterly inefficient in utilizing xylose, the two evolved strains converted (nearly) all of the xylose present in $15 \%$ hydrolyzate within about two days. Expressed in $q_{\text {xylose}}$, laboratory evolution brought

\section{Table 4 Physiological parameters of strains BP10001, IBB10A02 and IBB10B05 obtained from mixed glucose-xylose fermentation in $15 \%$ hydrolyzate}

\begin{tabular}{lccc}
\hline Parameter & BP10001 & IBB10A02 & IBB10B05 \\
\hline$q_{\text {Glucose }}\left(\mathrm{g} / \mathrm{g}_{\mathrm{CDW}} / \mathrm{h}\right)^{\mathrm{a} 1}$ & $2.81 \pm 0.04$ & $1.71 \pm 0.05$ & $2.90 \pm 0.22$ \\
$q_{\text {Xylose }}(\mathrm{g} / \mathrm{g}$ CDW/h) & $0.02 \pm 0.01$ & $0.23 \pm 0.01$ & $0.35 \pm 0.02$ \\
$\mu_{\text {max }}{ }^{\mathrm{a} 2}$ & $0.10 \pm 0.01$ & $0.10 \pm 0.01$ & $0.19 \pm 0.01$ \\
$Y_{\text {Ethanol }}(\mathrm{g} / \mathrm{g})$ & 0.40 & 0.39 & 0.39 \\
$\left(Y_{\text {Ethanol/available sugars }}(\mathrm{g} / \mathrm{g})\right)^{\mathrm{b}}$ & $(0.13)$ & $(0.38)$ & $(0.38)$ \\
$Y_{\text {Glycerol }}(\mathrm{g} / \mathrm{g})$ & 0.10 & 0.08 & 0.08 \\
$Y_{\text {Xylitol }}(\mathrm{g} / \mathrm{g})$ & 0.04 & 0.08 & 0.08 \\
$Y_{\text {Acetate }}(\mathrm{g} / \mathrm{g})$ & 0.04 & 0.04 & 0.04 \\
$Y_{\text {BM }}(\mathrm{g} / \mathrm{g})$ & 0.05 & 0.04 & 0.06 \\
C-recovery $(\%)$ & $103 \pm 1$ & $101 \pm 1$ & $104 \pm 1$
\end{tabular}

Data was obtained from two independent fermentations, mean errors of product coefficients were always below $14 \%$. Fermentation time courses are shown in Figure 3. Fermentation in $15 \%$ hydrolyzate: glucose to xylose ratio of approximately 2. Determined in the first ${ }^{\mathrm{a} 1} 3.5 \mathrm{~h}$ and ${ }^{\mathrm{a} 2} 6$ hours of fermentation; ${ }^{\mathrm{b}} Y_{\text {Ethanol/available sugars }}=\mathrm{c}$ (Ethanol produced in $50 \mathrm{~h}$ of fermentation)/c (Available glucose and xylose). about 11.5-fold (IBB10A02) and 17.5-fold (IBB10B05) enhancement of xylose utilization in $15 \%$ hydrolyzate as compared to BP10001. These improvement factors are of remarkable magnitude, and they therefore underscore the huge potential of evolutionary yeast strain engineering for biofuel process development.

Yield coefficients for mixed glucose-xylose fermentation in $15 \%$ hydrolyzate indicate good ethanol production ( $Y_{\text {Ethanol }}$ approximately $0.40 \mathrm{~g} / \mathrm{g}$ total sugars). Xylitol and glycerol were major by-products. A compilation of yield coefficients derived from the xylose phase is provided in Additional file 4. Compared to fermentations conducted in YX and 5\% hydrolyzate X $_{\mathrm{X}}$ media, xylitol yields ( $\left.Y_{\text {Xylitol/Xylose }}\right)$ in fermentations of the $15 \%$ hydrolyzate were notably elevated (up to $0.30 \mathrm{~g} / \mathrm{g}$; Additional files 2 and 4). The reason for high xylitol formation in 15\% hydrolyzate was not further pursued.

Although direct comparison is difficult due to different feedstock applied, we noticed that $Y_{\text {Ethanol }}$ (approximately $0.40 \mathrm{~g} / \mathrm{g}$ total sugars) and the final ethanol titer (approximately $20 \mathrm{~g} / \mathrm{L}$ ) for $15 \%$ hydrolyzate conversion by the evolved strains IBB10A02 and IBB10B05 (Table 4, Figure 3) were superior to the same fermentation parameters reported from other studies, where $Y_{\text {Ethanol }}$ did not exceed values of typically $0.37 \mathrm{~g} / \mathrm{g}$ total sugars when undiluted substrate was applied, and final ethanol titers were below $10 \mathrm{~g} / \mathrm{L}$ [34,35]. Higher ethanol yields as well as enhanced final ethanol titers were only achieved when 
glucose was fed continuously to the fermentation mixture, by running the process in SSF $[32,43]$ or separate hydrolysis and fermentation (SHF) run in fed-batch mode $[33,34]$. Consistently, we have shown that $q_{\text {xylose }}$ in mixed glucose-xylose fermentations by strain BP10001 is accelerated substantially by feeding low levels of glucose [22]. However, requirement for controlling the glucose feed tightly adds complexity of the process operation. Yeast strains producing high amounts of ethanol from xylose in simple batch fermentations are therefore of considerable interest for application in large-scale bioprocessing.

\section{Strain evolution as tool for process intensification: comparison of yeast strain performance under different substrate conditions}

Evidence from different studies, including the work presented herein, strongly supports the suggestion that evolutionary engineering of $S$. cerevisiae constitutes a powerful approach to achieve significant process intensification for xylose-to-ethanol fermentation [23-26,34,39]. Improvements in specific rate parameters and yield coefficients were shown to translate directly into pronounced enhancement of the final ethanol concentration, the process productivity, or both. Table 5 lists xylose-fermenting yeast strains generated by laboratory evolution and compares each strain to its corresponding progenitor. Consequences of evolutionary engineering were assessed in pure sugar substrate fermentations $[23,26,39]$, but also in lignocellulose hydrolyzate conversions [24,34]. Results show that in a wide range of media and cultivation conditions using pure sugar substrates, evolution caused effective enhancement in $q$ xylose (up to 8-fold) and conferred, or resulted in stabilization of, anaerobic growth on xylose (Table 5). The degree of xylose utilization and thus, the end concentration of ethanol were also increased by up to 4-fold. Even though the different studies are difficult to compare due to large variations in the experimental settings used, it is nonetheless clear that strain IBB10B05 features a notable

Table 5 Laboratory evolution of xylose-fermenting strains of S. cerevisiae as tool for process intensification: comparison of key process parameters reported for the progenitor strain and the evolved strain, respectively

\begin{tabular}{|c|c|c|c|c|c|c|c|}
\hline $\begin{array}{l}\text { Progenitor strain - } \\
\text { evolved strain } \\
\text { Genetic background }^{a}\end{array}$ & Fermentation condition $^{b}$ & $\begin{array}{l}\text { CSugar } \\
(g / L)^{c}\end{array}$ & $\begin{array}{c}q_{\text {Xylose }} \\
\left(\mathrm{g} / \mathrm{g}_{\mathrm{CDW}} / \mathrm{h}\right)\end{array}$ & $\begin{array}{c}C_{\text {Ethanol }} \\
(g / L)^{d}\end{array}$ & $\begin{array}{c}Y_{\text {Ethanol }} \\
\left(\mathrm{g} / \mathrm{g}_{\text {total sugars }}\right)\end{array}$ & $\underset{\left(h^{-1}\right)^{\mathrm{e}}}{\mu_{\max }}$ & Source \\
\hline TMB3001 - & MM & Glc: 50 & $0.08^{*}$ & $22^{*}$ & $0.38^{*}$ & $0.44^{\mathrm{Glc}}$ & \\
\hline TMB3001C1 & AN & Xyl: 50 & $0.31^{*}$ & $28^{*}$ & $0.40^{*}$ & $0.44^{\mathrm{Glc}}$ & {$[26]$} \\
\hline$X R / X D H / X K$ & LCD & & (3.9-fold) & (1.3-fold) & $(1.1-$ fold $)$ & $(-)$ & \\
\hline $\mathrm{H} 131-\mathrm{A} 3^{\mathrm{SB}-2}-$ & YE & Xyl: 40 & 0.26 & $4^{*}$ & 0.42 & $0.06^{\mathrm{Xyl}}$ & \\
\hline $\mathrm{H} 131-\mathrm{A} 3^{\mathrm{CS}}$ & AN & & 0.94 & $15^{*}$ & 0.43 & $0.12^{\mathrm{xyl}}$ & [39] \\
\hline$X I / P P P / T$ & LCD & & (3.6-fold) & (3.8-fold) & $(-)$ & (2-fold) & \\
\hline HDY.GUF5 - & YE, Pep & Glc: 36 & 0.13 & $18^{*}$ & 0.23 & n.a. & \\
\hline GS1.11-26 & Semi-AN & xyl: 37 & 1.10 & $34^{*}$ & 0.46 & n.a. & {$[23]$} \\
\hline$X I / P P P$ & $\mathrm{HCD}$ & & (8.5-fold) & (1.9-fold) & $(1.8-$ fold $)$ & $(-)$ & \\
\hline BP10001 - & YE & Xyl: 50 & 0.37 & 0.9 & 0.30 & - & \\
\hline IBB10B05 & AN & & 1.04 & 2.8 & 0.31 & $0.02^{\mathrm{Xyl}}$ & This study \\
\hline$X R / X D H / X K$ & LCD & & $(2.8-$ fold $)$ & (3.1-fold) & $(-)$ & $(-)$ & \\
\hline TMB3400 - & Wheat straw hydrolyzate, YE, salts, pH 5 & Glc: 7.6 & $0.20^{*}$ & 5.5 & 0.20 & - & \\
\hline KE6-13i & AN & Xyl: 38 & $0.04^{*}$ & 6 & 0.27 & - & [34] \\
\hline$X R / X D H / X K$ & HCD & & $(-)$ & $(1.1-$ fold $)$ & $(1.4-$ fold $)$ & $(-)$ & \\
\hline TMB3400 - & Spruce hydrolyzate, MM, pH 5 & & n.a. & $7.8^{*}$ & 0.40 & $0.07^{\mathrm{Glc}}$ & \\
\hline KE1-17 & AN & Glc: 18 & n.a. & $7.9^{*}$ & 0.43 & $0.08^{\mathrm{Glc}}$ & {$[24]$} \\
\hline$X R / X D H / X K$ & LCD & $x y \mid: 9$ & $(-)$ & $(-)$ & $(1.1-$ fold $)$ & (1.14-fold) & \\
\hline BP10001 - & Wheat straw hydrolyzate, YE, pH 6.5 & & 0.02 & 4 & 0.40 & $0.10^{\mathrm{Glc}}$ & \\
\hline IBB10B05 & AN & Glc: 32 & 0.35 & 21 & 0.39 & $0.19^{\mathrm{Glc}}$ & This study \\
\hline$X R / X D H / X K$ & HCD & Xyl: 16 & (17.5-fold) & (5.3-fold) & $(-)$ & (1.9-fold) & \\
\hline
\end{tabular}

${ }^{a}$ Strain background: PPP, overexpression of genes from the pentose phosphate pathway; $\mathrm{T}$, overexpression of the $\mathrm{HXT7}$ transporter; XDH, xylitol dehydrogenase; $\mathrm{XI}$, xylose isomerase; $\mathrm{XK}$, xylulose kinase; $\mathrm{XR}$, xylose reductase. ${ }^{\mathrm{b}} \mathrm{AN}$, anaerobic; $\mathrm{HCD}$, high cell density (start $\mathrm{OD}_{600}$ of fermentation $\geq 1$ ); $L C D$, low cell density (start $\mathrm{OD}_{600}$ of fermentation $\leq 0.5$ ); $\mathrm{MM}$, mineral medium; Pep, peptone; $\mathrm{YE}$, yeast extract. 'Initial sugar concentration of the substrate. ${ }^{\mathrm{d}}$ Ethanol produced within the first $50 \mathrm{~h}$ of fermentation or earlier, when sugars were depleted before. ${ }^{\mathrm{e}}$ Maximal growth rate on glucose (Glc) or xylose (Xyl). n.a., not analyzed; in parenthesis, improvement calculated from the evolved strain as compared to the progenitor strain; ${ }^{*}$ Data are derived from the time courses given in the respective publications. 
overall improvement in xylose fermentation capability. Effectiveness of the evolutionary procedure in IBB10B05 was remarkable in particular, considering that development of the progenitor strain BP10001 had involved only a minimum amount of metabolic engineering of the parent strain S. cerevisiae CEN.PK 113-5D. Interestingly, change of the sugar substrate to an unprocessed concentrated wheat straw hydrolyzate resulted in substantial ( $\geq 2$-fold) reinforcement of the process intensification effect of the strain evolution. This is reflected in very pronounced enhancement of $q_{\text {xylose }}$, the completeness of xylose consumption, and the final ethanol titer achievable with strain IBB10B05 as compared to strain BP10001. This result serves to emphasize the high robustness acquired by strain IBB10B05 during evolutionary engineering, despite the fact that increased resistance to conditions of the hydrolyzate was not selected for. Remarkably enough, yeast strain evolutions reported from other laboratories to specifically address tolerance against biomass-derived inhibitors did not achieve comparable improvements of strain performance during fermentation of lignocellulose hydrolyzates [24,34]. The lignocellulosic ethanol concentration of $21 \mathrm{~g} / \mathrm{L}$ reached with strain IBB10B05 therefore surpassed comparative values in Table 5 by 3 -fold or more.

\section{Conclusions}

The $q$ xylose is a complex physiological parameter of key technological importance in S. cerevisiae fermentations of lignocellulose hydrolyzates. Laboratory evolution of strain BP10001 to generate strains IBB10A02 and IBB10B05 resulted in effectively (up to 17.5-fold) enhanced $q$ xylose at complete perpetuation of the fermentation capabilities ( $Y_{\text {Ethanol}}$; $\left.q_{\text {Glucose }}\right)$ previously acquired by metabolic engineering. Strain IBB10B05 was identified as a particularly robust candidate for intensification of lignocellulose-to-bioethanol production processes.

\section{Methods}

\section{Chemicals and media used}

Unless mentioned otherwise, all chemicals were from Carl Roth + Co KG (Karlsruhe, Germany). Defined mineral (M-) medium was prepared as described elsewhere [15], except that riboflavin and folic acid were not added. For use of $\mathrm{M}$-medium under anaerobic conditions, ergosterol (10 mg/L), Tween $80(0.42 \mathrm{~g} / \mathrm{L})$ and $250 \mu \mathrm{L} / \mathrm{L}$ Antifoam 204 (all from Sigma-Aldrich, St Louis, MO, USA) were additionally supplied. YPD medium contained yeast extract $(10 \mathrm{~g} / \mathrm{L})$, peptone (from casein, 20 $\mathrm{g} / \mathrm{L})$ and glucose $(20 \mathrm{~g} / \mathrm{L})$. YX medium contained yeast extract $(10 \mathrm{~g} / \mathrm{L})$ and xylose $(58 \mathrm{~g} / \mathrm{L})$. Medium for anaerobic agar plate cultivation contained yeast extract (8 g/L), peptone (from casein, $10 \mathrm{~g} / \mathrm{L})$, xylose $(20 \mathrm{~g} / \mathrm{L})$, agar $(13 \mathrm{~g} / \mathrm{L})$, thioglycolate $(500 \mathrm{mg} / \mathrm{L})$, L-cysteine
(500 $\mathrm{mg} / \mathrm{L})$ and resazurin $(1 \mathrm{mg} / \mathrm{L})$. All media were brought to $\mathrm{pH} 6.5$, and the $\mathrm{pH}$ was verified after sterilization.

\section{Laboratory evolution of strain BP10001 and isolation of strains IBB10A02 and IBB10B05}

Strain BP10001 was previously constructed from S. cerevisiae CEN.PK 113-5D through genomic integration of genes encoding a doubly mutated (Lys ${ }^{274}$-to-Arg; Asn ${ }^{276}$-to-Asp) variant of XR from C. tenuis and the wild-type XDH from Galactocandida mastotermitis. Another gene copy of the endogenous xylulose kinase 1 was also integrated. Each gene was expressed under control of the constitutive TDH promoter and the CYC1 terminator. Laboratory evolution was carried out with strain BP10001 in two steps. Because evolutionary engineering of BP10001 will be described in a separate paper, only a brief summary is given here. Firstly, strain BP10001 was incubated in 15 mL glass tubes (Pyrex ${ }^{\circ}$ Brand 9825) containing $10 \mathrm{~mL}$ M-medium supplemented with $50 \mathrm{~g} / \mathrm{L}$ xylose $(\mathrm{XM})$. Each tube was inoculated to a cell density of $0.04 \mathrm{~g}_{\mathrm{CDW}} / \mathrm{L}$ and incubation was at $150 \mathrm{rpm}$ in a CERTOMAT BS-1 incubator shaker (Sartorius AG, Göttingen, Germany) at $30^{\circ} \mathrm{C}$ for 91 days. Afterwards, $400 \mu \mathrm{L}$ of cell suspension were plated on agar and incubated in an anaerobic jar at $30^{\circ} \mathrm{C}$ for 15 days. Single colonies were picked, transferred to new agar plates and further incubated for 5 days. Fast growing colonies were selected for cultivation in tubes as described above. The strain showing the highest $\mu_{\max }$ (strain IBB10A02), determined as the increase in optical density at $600 \mathrm{~nm}\left(\mathrm{OD}_{600}\right)$ over time, was used for further evolutionary engineering by repetitive batches. Hence, strain IBB10A02 was grown (start $\mathrm{OD}_{600}$ approximately 0.05 ) under anaerobic conditions in sealed flasks containing XM-medium. At mid-exponential phase $\left(\mathrm{OD}_{600}\right.$ approximately 1$)$, cells were transferred to a new batch $\left(\mathrm{OD}_{600}\right.$ approximately 0.05$)$ containing fresh XM-medium. Cells were again cultivated until the mid-exponential phase was reached. This procedure was repeated until the observed $\mu_{\max }$ was approximately doubled. Positive strains were isolated under anaerobic conditions and tested with respect to $\mu_{\max }$ and $Y_{\text {Xylitol }}$ and the best performing strain was termed IBB10B05.

\section{Preparation of the lignocellulosic feedstock}

Austrian wheat straw was utilized. The wheat straw was air-dried to a water content of approximately $10 \%(\mathrm{w} / \mathrm{w})$ and the fibers were chaffed in a shredder (GE 365; Viking, Tyrol, Austria) to reduce the fiber length to an average of 3 to $4 \mathrm{~cm}$. Further, the wheat straw was treated by steam explosion at $200^{\circ} \mathrm{C}, 15$ bar for $10 \mathrm{~min}$ with a water to wheat straw ratio of 3 . After cooling the wheat straw was stored at $-20^{\circ} \mathrm{C}$ in plastic bags. Dry mass (DM) and water-insoluble content (WIS) were 
analyzed in triplicates. For DM determination, a moisture analyzer operated at $105^{\circ} \mathrm{C}$ (MA 50; Sartorius AG) was used. For WIS determination, $2 \mathrm{~g}$ of the wheat straw was washed with $50 \mathrm{~mL}$ of $50^{\circ} \mathrm{C}$ warm water, dried at $105^{\circ} \mathrm{C}$ for $24 \mathrm{~h}$ and weighed. Additionally, the content of structural carbohydrates, lignin and ash in the wheat straw was analyzed in double determination, following the protocol of the National Renewable Energy Laboratory (NREL) [44]. The resulting compositional analysis is depicted in Table 1. Besides the main sugars glucose and xylose, only small amounts of mannose $(<1.9 \%$ DM wheat straw) and arabinose $(<0.9 \% \mathrm{DM}$ wheat straw) could be detected, and they are summarized as 'others' in Table 1.

\section{Enzymatic hydrolysis}

Enzymes for wheat straw hydrolysis were produced using the Trichoderma reesei strain SVG17 as described previously [45]. Briefly, the fungus was cultivated in a BIOSTAT C4 bioreactor (Sartorius AG) with 5 L working volume. Pretreated wheat straw $(3 \%(\mathrm{w} / \mathrm{v}))$ was the sole carbon source. Fermentations were run for 7 to 9 days $\left(30^{\circ} \mathrm{C}, \mathrm{pH} 4.5,20 \%\right.$ dissolved oxygen), until no further increase in cellulase activity was detected. Cellulase activity was measured with the filter paper unit (FPU) assay as recommended by the International Union of Pure and Applied Chemistry (IUPAC) [46]. The enzyme solution was harvested by centrifugation $(4,420 \mathrm{~g}$, $4^{\circ} \mathrm{C}, 20 \mathrm{~min}$, Sorvall RC-5B; DuPont Instruments, Wilmington, DE, USA) and the supernatant filtered sterile (Whatman Klari-Flex System; GE Healthcare, Little Chalfont, UK). Hydrolyzates were freshly prepared shortly before fermentation from one batch of pretreated wheat straw. The substrate loading was 5\% and $15 \%$ DM wheat straw and the enzyme loading was 25 FPU/g DM. Reaction was performed in $10 \mathrm{mM}$ sodium acetate buffer $(\mathrm{pH} 4.8)$ in $500 \mathrm{~mL}$ shaken flasks with ground in stoppers filled with $200 \mathrm{~mL}$ wheat straw suspension. The wheat straw suspension was autoclaved and the enzyme solution sterile filtrated. Incubation was at $50^{\circ} \mathrm{C}$ and $200 \mathrm{rpm}$ in an incubator shaker (CERTOMAT BS-1) for $48 \mathrm{~h}$. Afterwards, the hydrolyzate was heated to $100^{\circ} \mathrm{C}$ for $15 \mathrm{~min}$ and remaining solids were removed by centrifugation $\left(4,420 \mathrm{~g}, 4^{\circ} \mathrm{C}, 10 \mathrm{~min}\right.$, Sorvall $\mathrm{RC}-5 \mathrm{~B})$. The $\mathrm{pH}$ of the hydrolyzate was set to 6.5 with $1 \mathrm{M} \mathrm{NaOH}$ solution. The sugar content of the hydrolyzates was analyzed by HPLC as described below. We noted variation in the composition of the $15 \%$ hydrolyzates prepared in different hydrolysis runs $(\mathrm{N}>10)$. Glucose and xylose were present at $42.8 \pm 3.9 \mathrm{~g} / \mathrm{L}$ and $21.1 \pm 3.1 \mathrm{~g} / \mathrm{L}$, respectively. Acetic acid concentration was $3.6 \pm 0.5 \mathrm{~g} / \mathrm{L}$. Mannose $(<0.7 \mathrm{~g} / \mathrm{L})$ and galactose $(<0.2 \mathrm{~g} / \mathrm{L})$ were present in small amounts. Cellobiose showed the highest variation in the range 1 to $5 \mathrm{~g} / \mathrm{L}$.
Activity of $\beta$-glucosidase, which is the enzyme hydrolyzing cellobiose into glucose, may have been limiting in some of the cellulase preparations applied to hydrolysis. Reasons for variation in sugar content of different hydrolyzates are not completely clear at this time, and their examination was left for consideration in the future. However, each yeast strain was used in multiple fermentation experiments $(\mathrm{N} \geq 3)$ and the reported parameters were not affected significantly by the relevant variations in hydrolyzate composition.

\section{Shaken bottle fermentations}

Reactions were performed anaerobically at $30^{\circ} \mathrm{C}$. About $80 \%$ of the total volume was wheat straw hydrolyzate and the remainder volume was composed of media supplementation (10\%) and inoculum (10\%). In fermentations of $5 \%$ hydrolyzate, $\mathrm{M}$-medium and xylose $(58 \mathrm{~g} / \mathrm{L})$ were added ( $5 \%$ hydrolyzate $)_{\mathrm{X}}$ ). The $15 \%$ hydrolyzate fermentations were supplemented with yeast extract $(10 \mathrm{~g} / \mathrm{L})$. Starting $\mathrm{OD}_{600}$ in fermentations of the hydrolyzates was 5. Additionally, fermentations were conducted in YX media, with a starting $\mathrm{OD}_{600}$ of 0.5 . Seed and starter cultures were prepared in M-media with additional glucose $(20 \mathrm{~g} / \mathrm{L})$ for fermentations supplemented with mineral media. All others were prepared in YPD media. Yeast strains were stored at $-70^{\circ} \mathrm{C}$ in glycerol stocks and initially plated on YPD agar. Incubation was at $30^{\circ} \mathrm{C}$ for $48 \mathrm{~h}$. Afterwards, cells were transferred to $500 \mathrm{~mL}$ shaken flasks filled with $50 \mathrm{~mL}$ of the respective media and incubated at $30^{\circ} \mathrm{C}$ overnight. Subsequently, cells were transferred to $300 \mathrm{~mL}$ of fresh media in $1,000 \mathrm{~mL}$ shaken flasks. Starting $\mathrm{OD}_{600}$ was 0.05 and incubation was at $30^{\circ} \mathrm{C}$ until the exponential growth phase was reached. Cells were harvested by centrifugation $\left(4,420 \mathrm{~g}, 4^{\circ} \mathrm{C}, 20 \mathrm{~min}\right.$, Sorvall RC-5B) and the cell pellet was washed and resuspended in $\mathrm{NaCl}$ solution $(9 \mathrm{~g} / \mathrm{L})$. Fermentations were accomplished in glass bottles tightly sealed with rubber septa ( $90 \mathrm{~mL}$ working volume). The bottles were sparged with $\mathrm{N}_{2}$ prior to and shortly after inoculation. Incubation was at $30^{\circ} \mathrm{C}$ and $180 \mathrm{rpm}$ (CERTOMAT BS-1).

\section{Sampling and quantitative analysis of sugars and metabolites}

Samples of $1.5 \mathrm{~mL}$ were frequently removed from yeast fermentations, centrifuged $\left(15,700 \mathrm{~g}, 4^{\circ} \mathrm{C}, 10 \mathrm{~min}\right.$, Centrifuge 5415 R; Eppendorf, Hamburg, Germany) and the supernatant stored at $-20^{\circ} \mathrm{C}$ for HPLC analysis. Cell growth was recorded as increase in $\mathrm{OD}_{600}$. Cell dry weight (CDW) was determined as follows. $10 \mathrm{~mL}$ of cell suspension was harvested by centrifugation $\left(3,220 \mathrm{~g}, 4^{\circ} \mathrm{C}, 10 \mathrm{~min}\right.$, Centrifuge 5810 R; Eppendorf), and the cell pellet washed with $10 \mathrm{~mL}$ and resuspended in $1 \mathrm{~mL} \mathrm{NaCl}$ solution $(9 \mathrm{~g} / \mathrm{L})$. Subsequently, the cell suspension was transferred to pre-dried 
$\left(105^{\circ} \mathrm{C}, 12 \mathrm{~h}\right)$ glass vials and then dried until weight constancy $\left(105^{\circ} \mathrm{C}\right.$, approximately $\left.12 \mathrm{~h}\right)$. The CDW/OD 600 correlation was determined to be 0.37 and it was established in triple determination. External fermentation products (ethanol, glycerol, acetate and xylitol) were analyzed by HPLC (Merck-Hitachi LaChrom system, L-7250 autosampler, L-7490 RI detector, L-7400 UV detector; Merck, Whitehouse Station, NJ, USA). The system was equipped with an Aminex HPX-87H column and an Aminex Cation $\mathrm{H}$ guard column (both Bio-Rad, Hercules, CA, USA). The operation temperature was $65^{\circ} \mathrm{C}$ and the flow rate of the mobile phase ( $5 \mathrm{mM}$ sulfuric acid) was $0.6 \mathrm{~mL} / \mathrm{h}$. Carbohydrates (glucose, xylose, arabinose, mannose, galactose and cellobiose) were determined with the same HPLC system but equipped with an Aminex HPX-87P column and a de-ashing guard column (both Bio-Rad). Operation temperature was $80^{\circ} \mathrm{C}$ for the main column and room temperature for the guard column. The mobile phase was deionized water with a flow rate of $0.4 \mathrm{~mL} / \mathrm{min}$.

\section{Data processing and calculations}

Reported yield coefficients were always based on mass. Yield coefficients for the xylose phase (Additional files 2 and 4) were calculated for the second phase of the fermentation when glucose was depleted. Carbon balance calculations included metabolite and biomass yields. For the biomass yield a value of $26.4 \mathrm{~g} / \mathrm{C}$-mol was utilized [47]. It was further assumed that $1 \mathrm{~mol} \mathrm{CO}_{2}$ was formed per mol acetate and ethanol. $q_{\text {Glucose }}$ and $q_{\text {xylose }}$ were calculated by plotting glucose and xylose concentration against fermentation time and fitting the concentration decay with a suitable equation. The first derivative of the respective equation, normalized on the CDW, was used to calculate the uptake rate, which is given in $\mathrm{g} / \mathrm{g}_{\mathrm{CDW}} / \mathrm{h}$. Similar to previously published studies [22,40], qxylose was observed to decrease with reaction time (Additional file 5). Values of $q_{\text {xylose }}$ reported herein are therefore calculated from the initial period of the xylose phase (when glucose was already depleted fully) and represent arithmetic means of at least two determinations made within the first 5 hours of this phase [48]. The courses of $q$ xylose over time are provided in Additional file 5.

\section{Additional files}

Additional file 1: Fermentation of $Y X$ media using strains (A) BP10001, (B) IBB10A02 and (C) IBB10B05. Full diamonds, xylose; empty triangles, glycerol; empty squares, xylitol; empty circles, ethanol; crosses, $\mathrm{OD}_{600}$.

Additional file 2: Product yields obtained in fermentations of $\mathrm{YX}$ media utilizing strains BP1000, IBB10A02 and IBB10B05.

Additional file 3: 'Glucose phase' of mixed glucose-xylose

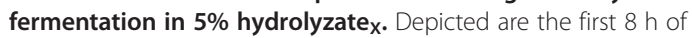
fermentation using strains (A) BP10001, (B) IBB10A02 and (C) IBB10B05. Full time courses are depicted in Figure 2. Full diamonds, xylose; crosses, glucose; empty triangles, glycerol; empty squares, xylitol; empty circles, ethanol.

Additional file 4: Product yields obtained in the 'xylose phase' in fermentations of $5 \%$ hydrolyzate h $_{x}$ and $15 \%$ hydrolyzate utilizing strains BP10001, IBB10A02 and IBB10B05.

Additional file 5: $q_{\text {Xylose }}$ is decreasing with fermentation time. Depicted is the $q_{\text {xylose }}$ over fermentation time in fermentation of (A) YX (B) 5\% hydrolyzate $x$ and (C) 15\% hydrolyzate using strains BP10001 (empty triangles), IBB10A02 (filled squares) and IBB10B05 (filled circles).

\section{Abbreviations}

AN: Anaerobic; ATP: Adenosine triphosphate; CDW: Cell dry weight; DM: Dry mass; FPU: filter paper unit; Glc: Glucose; HCD: High cell density; HPLC: High performance liquid chromatography; IUPAC: International Union of Pure and Applied Chemistry; LCD: Low cell density; MM/M-medium: Mineral medium; NADH: Nicotinamide adenine dinucleotide; NADP: Nicotinamide adenine dinucleotide phosphate; NREL: National Renewable Energy Laboratory; $\mathrm{OD}_{600}$ : Optical density at $600 \mathrm{~nm}$; Pep: Peptone; PPP: Pentose phosphate pathway; 9 xylose/Glucose: Specific xylose/glucose uptake rate; Semi-AN: Semianaerobic; SHCF: Separate hydrolysis and co-fermentation; SHF: Separate hydrolysis and fermentation; SSF: Simultaneous saccharification and fermentation; WIS: Water-insoluble content; XDH: Xylitol dehydrogenase; $\mathrm{XI}$ : Xylose isomerase; XM-medium: Xylose mineral medium; $X \mathrm{R}$ : Xylose reductase; $X y l: X y l o s e ; X y l / G l c: X y l o s e / g l u c o s e ; Y_{\text {Ethanol/Glycerol/Xylitol/ }}$ Acetate: Ethanol/glycerol/xylitol/acetate yield; YPD: Yeast extract peptone dextrose; YX: Yeast extract xylose; $\mu_{x y l o s e}:$ Maximum specific anaerobic growth rate.

\section{Competing interests}

The authors declare that they have no competing interests.

\section{Authors' contributions}

VN, SK, MK and BN designed the research. VN and SK planned the experiments. VN, SK, KL, GM and MW performed the experiments and analyzed data. The manuscript was written from contributions of all authors. VN and BN wrote the paper. All authors read and approved the final manuscript.

\section{Acknowledgements}

We would like to thank Rupert Köberl from the Technologie- und Dienstleistungszentrum Ennstal GmbH (Reichraming, Austria) for providing the pretreated wheat straw.

Received: 20 December 2013 Accepted: 18 March 2014 Published: 3 April 2014

\section{References}

1. Chundawat SPS, Beckham GT, Himmel ME, Dale BE: Deconstruction of lignocellulosic biomass to fuels and chemicals. Annu Rev Chem Biomol Eng 2011, 2:121-145.

2. Hahn-Hägerdal B, Galbe M, Gorwa-Grauslund MF, Lidén G, Zacchi G: Bio-ethanol: the fuel of tomorrow from the residues of today. Trends Biotechnol 2006, 24:549-556.

3. Talebnia F, Karakashev D, Angelidaki I: Production of bioethanol from wheat straw: an overview on pretreatment, hydrolysis and fermentation. Bioresour Technol 2010, 101:4744-4753.

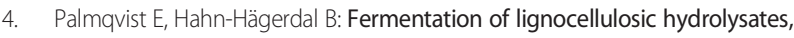
II: inhibitors and mechanisms of inhibition. Bioresour Techno/ 2000, 1:25-33.

5. van Maris A, Abbott D, Bellissimi E, van den Brink J, Kuyper M, Luttik M, Wisselink H, Scheffers W, van Dijken J, Pronk J: Alcoholic fermentation of carbon sources in biomass hydrolyzates by Saccharomyces cerevisiae: current status. Antonie Van Leeuwenhoek 2006, 90:391-418.

6. Hahn-Hägerdal B, Karhumaa K, Fonseca C, Spencer-Martins I, Gorwa-Grauslund M: Towards industrial pentose-fermenting yeast strains. Appl Microbiol Biotechnol 2007, 74:937-953.

7. Matsushika A, Inoue H, Kodaki T, Sawayama S: Ethanol production from xylose in engineered Saccharomyces cerevisiae strains: current state and perspectives. Appl Microbiol Biotechnol 2009, 84:37-53.

8. Sims REH, Mabee W, Saddler JN, Taylor M: An overview of second generation biofuel technologies. Bioresour Technol 2010, 101:1570-1580. 
9. Brat $D$, Boles $E$, Wiedemann B: Functional expression of a bacterial xylose isomerase in Saccharomyces cerevisiae. Appl Environ Microbiol 2009, 75:2304-2311

10. Ho NW, Chen Z, Brainard AP: Genetically engineered Saccharomyces yeast capable of effective cofermentation of glucose and xylose. Appl Environ Microbiol 1998, 64:1852-1859.

11. Karhumaa K, Garcia Sanchez R, Hahn-Hägerdal B, Gorwa-Grauslund M: Comparison of the xylose reductase-xylitol dehydrogenase and the xylose isomerase pathways for xylose fermentation by recombinant Saccharomyces cerevisiae. Microb Cell Fact 2007, 6:5.

12. Kotter $P$, Amore $R$, Hollenberg $C P$, Ciriacy M: Isolation and characterization of the Pichia stipitis xylitol dehydrogenase gene, XYL2, and construction of a xylose-utilizing Saccharomyces cerevisiae transformant. Curr Genet 1990, 18:493-500.

13. van Maris A, Winkler A, Kuyper M, de Laat W, van Dijken J, Pronk J: Development of efficient xylose fermentation in Saccharomyces cerevisiae: xylose isomerase as a key component. Adv Biochem Eng Biotechnol 2007, 108:179-204

14. Viikari L, Vehmaanperä J, Koivula A: Lignocellulosic ethanol: from science to industry. Biomass Bioenergy 2012, 46:13-24.

15. Jeppsson M, Bengtsson O, Franke K, Lee H, Hahn-Hägerdal B, Gorwa-Grauslund MF: The expression of a Pichia stipitis xylose reductase mutant with higher $\mathrm{K}(\mathrm{M})$ for NADPH increases ethanol production from xylose in recombinant Saccharomyces cerevisiae. Biotechnol Bioeng 2006, 93:665-673.

16. Petschacher B, Nidetzky B: Engineering Candida tenuis xylose reductase for improved utilization of NADH: Antagonistic effects of multiple side chain replacements and performance of site-directed mutants under simulated in vivo conditions. Appl Environ Microbiol 2005, 71:6390-6393.

17. Matsushika A, Watanabe S, Kodaki T, Makino K, Inoue H, Murakami K, Takimura O, Sawayama S: Expression of protein engineered NADP +-dependent xylitol dehydrogenase increases ethanol production from xylose in recombinant Saccharomyces cerevisiae. Appl Microbiol Biotechnol 2008, 81:243-255.

18. Krahulec $S$, Klimacek M, Nidetzky B: Analysis and prediction of the physiological effects of altered coenzyme specificity in xylose reductase and xylitol dehydrogenase during xylose fermentation by Saccharomyces cerevisiae. J Biotechnol 2012, 158:192-202.

19. Krahulec S, Longus K, Klimacek M, Nidetzky B: On the role of a balanced cofactor recycling between xylose reductase and xylitol dehydrogenase in recombinant xylose fermenting strains of Saccharomyces cerevisiae. J Biotechnol 2010, 150:12

20. Petschacher B, Nidetzky B: Altering the coenzyme preference of xylose reductase to favor utilization of $\mathrm{NADH}$ enhances ethanol yield from xylose in a metabolically engineered strain of Saccharomyces cerevisiae. Microb Cell Fact 2008, 7:9.

21. Krahulec $S$, Klimacek M, Nidetzky B: Engineering of a matched pair of xylose reductase and xylitol dehydrogenase for xylose fermentation by Saccharomyces cerevisiae. Biotechnol J 2009, 4:684-694.

22. Krahulec S, Petschacher B, Wallner M, Longus K, Klimacek M, Nidetzky B: Fermentation of mixed glucose-xylose substrates by engineered strains of Saccharomyces cerevisiae: role of the coenzyme specificity of xylose reductase, and effect of glucose on xylose utilization. Microb Cell Fact 2010, 9:16.

23. Demeke M, Dietz H, Li Y, Foulquie-Moreno M, Mutturi S, Deprez S, Den Abt T, Bonini B, Liden G, Dumortier F, Verplaetse A, Boles E, Thevelein JM: Development of a D-xylose fermenting and inhibitor tolerant industrial Saccharomyces cerevisiae strain with high performance in lignocellulose hydrolyzates using metabolic and evolutionary engineering. Biotechnol Biofuels 2013, 6:89.

24. Koppram R, Albers E, Olsson L: Evolutionary engineering strategies to enhance tolerance of xylose utilizing recombinant yeast to inhibitors derived from spruce biomass. Biotechnol Biofuels 2012, 5:32.

25. Sauer U: Evolutionary engineering of industrially important microbial phenotypes. In Metabolic Engineering, Volume 73. Edited by Nielsen J, Eggeling L, Dynesen J, Gárdonyi M, Gill R, de Graaf A, Hahn-Hägerdal B, Jönsson L, Khosla C, Licari R. Heidelberg: Springer Berlin; 2001:129-169.

26. Sonderegger M, Sauer U: Evolutionary engineering of Saccharomyces cerevisiae for anaerobic growth on xylose. Appl Environ Microbiol 2003, 69:1990-1998

27. Ha SJ, Galazka JM, Kim SR, Choi JH, Yang X, Seo JH, Glass NL, Cate JH, Jin YS Engineered Saccharomyces cerevisiae capable of simultaneous cellobiose and xylose fermentation. Proc Natl Acad Sci USA 2011, 108:504-509.
28. Kuyper M, Toirkens MJ, Diderich JA, Winkler AA, van Dijken JP, Pronk JT: Evolutionary engineering of mixed-sugar utilization by a xylose-fermenting Saccharomyces cerevisiae strain. FEMS Yeast Res 2005, 5:925-934.

29. Almeida JRM, Karhumaa K, Bengtsson O, Gorwa-Grauslund M-F: Screening of Saccharomyces cerevisiae strains with respect to anaerobic growth in non-detoxified lignocellulose hydrolyzate. Bioresour Technol 2009, 100:3674-3677.

30. Kim S, Dale B: Global potential bioethanol production from wasted crops and crop residues. Biomass Bioenergy 2004, 4:361-375.

31. Erdei B, Barta Z, Sipos B, Reczey K, Galbe M, Zacchi G: Ethanol production from mixtures of wheat straw and wheat meal. Biotechnol Biofuels 2010, 3:16.

32. Olofsson K, Palmqvist B, Liden G: Improving simultaneous saccharification and co-fermentation of pretreated wheat straw using both enzyme and substrate feeding. Biotechnol Biofuels 2010, 3:17.

33. Erdei B, Franko B, Galbe M, Zacchi G: Separate hydrolysis and co-fermentation for improved xylose utilization in integrated ethanol production from wheat meal and wheat straw. Biotechnol Biofuels 2012, 5:12.

34. Erdei B, Frankó B, Galbe M, Zacchi G: Glucose and xylose co-fermentation of pretreated wheat straw using mutants of $S$. cerevisiae TMB3400. J Biotechnol 2013, 164:50-58

35. Tomas-Pejo E, Oliva J, Ballesteros M, Olsson L: Comparison of SHF and SSF processes from steam-exploded wheat straw for ethanol production by xylose-fermenting and robust glucose-fermenting Saccharomyces cerevisiae strains. Biotechnol Bioeng 2008, 6:1122-1131.

36. Ballesteros I, Negro MJ, Oliva JM, Cabanas A, Manzanares P, Ballesteros M: Ethanol production from steam-explosion pretreated wheat straw. Appl Biochem Biotechnol 2006, 129-132:496-508.

37. Kadam KL, Newman MM: Development of a low-cost fermentation medium for ethanol production from biomass. Appl Microbiol Biotechnol 1997, 47:625-629.

38. Jorgensen $\mathrm{H}$ : Effect of nutrients on fermentation of pretreated wheat straw at very high dry matter content by Saccharomyces cerevisiae. Appl Biochem Biotechnol 2009, 153:44-57.

39. Zhou H, Cheng JS, Wang BL, Fink GR, Stephanopoulos G: Xylose isomerase overexpression along with engineering of the pentose phosphate pathway and evolutionary engineering enable rapid xylose utilization and ethanol production by Saccharomyces cerevisiae. Metab Eng 2012, 14:611-622.

40. Novy V, Krahulec S, Longus K, Klimacek M, Nidetzky B: Co-fermentation of hexose and pentose sugars in a spent sulfite liquor matrix with genetically modified Saccharomyces cerevisiae. Bioresour Technol 2013, 130:439-448.

41. Casey E, Sedlak M, Ho NW, Mosier NS: Effect of acetic acid and pH on the co-fermentation of glucose and xylose to ethanol by a genetically engineered strain of Saccharomyces cerevisiae. FEMS Yeast Res 2010, 10:385-393.

42. Meinander NQ, Boels I, Hahn-Hägerdal B: Fermentation of xylose/glucose mixtures by metabolically engineered Saccharomyces cerevisiae strains expressing XYL1 and XYL2 from Pichia stipitis with and without overexpression of TAL1. Bioresour Technol 1999, 68:79-87.

43. Olofsson K, Rudolf A, Liden G: Designing simultaneous saccharification and fermentation for improved xylose conversion by a recombinant strain of Saccharomyces cerevisiae. J Biotechnol 2008, 134:112-120.

44. Sluiter A, Hames B, Ruiz R, Scarlata C, Sluiter J, Templeton D, Crocker D: Determination of Structural Carbohydrates and Lignin in Biomass, Technical Report NREL/TP-510-42618. Golden, CO: National Renewable Energy Laboratory; 2011.

45. Esterbauer H, Steiner W, Labudova I, Hermann A, Hayn M: Production of Trichoderma cellulase in laboratory and pilot scale. Bioresour Technol 1991 36:51-65.

46. Ghose T: Measurement of cellulase activities. Pure App/ Chem 1987, 2:257-268.

47. Lange HC, Heijnen JJ: Statistical reconciliation of the elemental and molecular biomass composition of Saccharomyces cerevisiae. Biotechnol Bioeng 2001, 75:334-344

48. Klimacek M, Krahulec S, Sauer U, Nidetzky B: Limitations in xylose-fermenting Saccharomyces cerevisiae, made evident through comprehensive metabolite profiling and thermodynamic analysis. Appl Environ Microbiol 2010, 76:7566-7574.

doi:10.1186/1754-6834-7-49

Cite this article as: Novy et al:: Process intensification through microbial strain evolution: mixed glucose-xylose fermentation in wheat straw hydrolyzates by three generations of recombinant Saccharomyces cerevisiae. Biotechnology for Biofuels 2014 7:49. 